\title{
Prototipe Kursi Roda Elektrik dengan Kendali Joystick dan Smartphone
}

\author{
Andy Sadewa Junior ${ }^{1}$, Fatchul Arifin ${ }^{2}$ \\ 1,2Program Studi Teknik Elektronika Fakultas Teknik Universitas Negeri Yogyakarta \\ E-mail: sadewa847@gmail.com
}

\begin{abstract}
Wheelchairs are one of the walking aids for people with disabilities and also for people who are unable to move from one place to another. The purpose of this research was to build hardware and software into a wheelchair prototype that can be controlled with joysticks and smartphones and to know its performance. The method in making the final project consists of the stages of need identification, requirements analysis, system design, tool making, tool testing and data collection. Based on the testing that has been done, the results are obtained that the control input from the smartphone through the application and also the joystick produces the output of the wheelchair prototype movement according to the instructions that have been set as input. The maximum distance of the control system from the smartphone is 0-10 meters either with obstacles or without obstacles. The response of the wheelchair prototype device has an average error of 0.024. Smartphone applications that are used as controls can be installed on the latest Android version "Nougat" and 4 versions of Android below. The speed of the wheelchair prototype on the joystick control matches the value of the resistance issued by the joystick module.
\end{abstract}

Keywords: Wheelchairs, Smartphone, DC motor, Arduino Nano

\begin{abstract}
ABSTRAK
Kursi roda adalah salah satu alat bantu berjalan untuk orang-orang penyandang cacat kaki dan juga untuk orang yang tidak mampu berpindah dari satu tempat ke tempat lainya. Tujuan penelitian ini adalah untuk membangun perangkat keras dan perangkat lunak menjadi sebuah prototype kursi roda yang dapat dikendalikan dengan joystik dan smartphone serta mengetahui unjuk kerjanya. Metode dalam pembuatan proyek akhir terdiri dari tahap identifikasi kebutuhan, analisis kebutuhan, perancangan sistem, pembuatan alat, pengujian alat dan pengambilan data. Berdasarkan pengujian yang telah dilakukan, maka didapatkan hasil bahwa masukan pengendalian dari smartphone melalui aplikasi dan juga joystick menghasilkan keluaran gerakan prototype kursi roda sesuai instruksi yang telah diset sebagai masukan. Jarak maksimum sistem kontrol dengan smartphone sejauh 0-10 meter baik dengan halangan ataupun tanpa halangan. Respon perangkat prototype kursi roda memiliki ratarata eror sebesar 0,024. Aplikasi smartphone yang digunakan sebagai kendali dapat diinstal pada versi android terbaru "nougat" dan 4 versi android dibawahnya. Kecepatan prototype kursi roda pada kendali joystick sesuai dengan nilai resistansi yang dikeluarkan oleh modul joystick.
\end{abstract}

Kata kunci: Kursi roda, Smartphone, joystick, Motor DC, Arduino Nano

\section{PENDAHULUAN}

Kursi roda merupakan alat di bidang kesehatan yang digunakan untuk membantu orang-orang yang mempunyai keterbatasan fisik terutama bagi mereka penyandang cacat kaki dan ketidakmampuan berjalan dikarenakan kondisi kesehatan yang tidak baik. Ketidakmampuan berjalan ini bisa disebabkan oleh berbagai macam hal, seperti penyakit, cedera pada anggota gerak terutama pada bagian kaki dan juga bisa disebabkan oleh kecacatan fisik yang sudah diderita sejak lahir. Berdasarkan Rekapitulasi jumlah Penyandang Masalah Kesejahteraan Sosisal (PMKS) oleh Kementrian Sosial pada tahun 2008 perjenis PMKS, jumlah penyandang cacat atau disabilitas yang ada di indonesia sebanyak 1.544.184 jiwa [1]. Menurut hasil data dari Sensus Penduduk yang dilakukan oleh Badan Pusat Statistik (BPS) 
pada tahun 2010, dari jumlah penduduk Indonesia yang berusia di atas 10 tahun sebanyak 191,7 juta jiwa didapatkan bahwa ada 190,8 juta jiwa dinyatakan mengalami kesulitan fungsional berdasarkan data kuesioner C1 [2]. Dari data kesulitaan funsgsional tersebut, kesulitan berjalan atau menaiki tangga sejumlah 2.432 dengan kondisi sedang dam 656 orang mengalami kondisi yang parah atau dengan prosentase $1,62 \%$. Dengan data tersebut diketahui bahwa kesulitan berjalan atau menaiki tangga merupakan kesulitan fungsional yang cukup banyak selain permaslahan pengelihatan.

Pada umumnya kursi roda yang sering digunakan oleh pasien di rumah sakit yang mempunyai keterbatasan fisik masih menggunakan sistem manual. Dimana penggunaan kursi roda dilakukan oleh penggunanya sendiri dengan cara memutar roda pada kursi dengan menggunakan tangan. Akan tetapi tidak semua pengguna kursi roda memiliki kemampuan untuk menggerakan kursi roda. Idealnya kursi roda digunakan agar si pengguna bisa bergerak bebas mengatur pergerakan sesuai yang dikehendakinya, akan tetapi yang terjadi di lapangan tidak semua pengguna dapat melakukanya kerena memiliki keterbatasan di bagian tangan. Sehingga membutuhkan alat yang dapat membantu mobilitas pengguna kursi roda berupa kursi roda otomatis. Akan tetapi kursi roda elektrik dengan tenaga baterai dan dikontrol dengan menggunakan joystick, per unit kursi roda seharga Rp 19.500.000,-. Harga tersebut terbilang mahal untuk sebagian besar masyarakat. Pada tahun 2010 koran Tempo memuat sebuah berita tentang 80 persen pengguna kursi roda di Daerah Istimewa Yogyakarta adalah masyarakat kurang mampu [3]. Banyak dari masyarakat kurang mampu masih menggunakan kursi yang masih dioprasikan dengan cara manual.

Manual stick analog dapat digunakan sebagai kendali kursi roda [4]. Kendali pergerakan kursi roda dapat menggunakan tombol tombol pengendali yang terdiri dari tombol untuk maju, belok kiri dan belok kanan [5]. Kendali pergerakan kursi roda juga bias dilakukan dengan Sensor Elektromiograf [6]. Joystick dapat digunakan sebagai kendali pergerakan kursi roda [7]. Kursi roda cerdas lainnya menggunakan pergerakan kepala sebagai pengendalinya [8]. Otomatisasi kursi roda menggunakan speech recognition sebelumnya telah dilakukan [9]. Penggunaan perintah suara berbasis aplikasi android juga diterapkan pada kursi roda [10]. Mempertimbangkan faktor ekonomis dan kemudahan, maka penulis merancang kursi roda otomatis dengan judul "Prototype Kursi Roda Elektrik Dengan Kendali Joystick Dan Smartphone". Melalui pembuatan alat ini diharapkan dapat membantu perngguna kursi roda yang kesulitan dalam menggerakan kursi rodanya dikarenakan suatu keterbatasan.

\section{METODE}

Prototype Kursi Roda Elektrik Dengan Kendali Joystick Dan Smartphone ini dibuat untuk mempermudah pengendalian kursi roda. Simulator kursi roda digerakan oleh dua buah motor DC melalui perintah yang dimasukan melalui aplikasi di smartphone dan juga nilai resistansi yang dihasilkan oleh gerak modul joystick. Metode dalam pembuatan perangkat terdiri dari tahap identifikasi kebutuhan, perancangan sistem, pembuatan alat dan pengujian alat Gambar 1 menunjukkan tahapan pembuatan perangkat yang dilakukan.

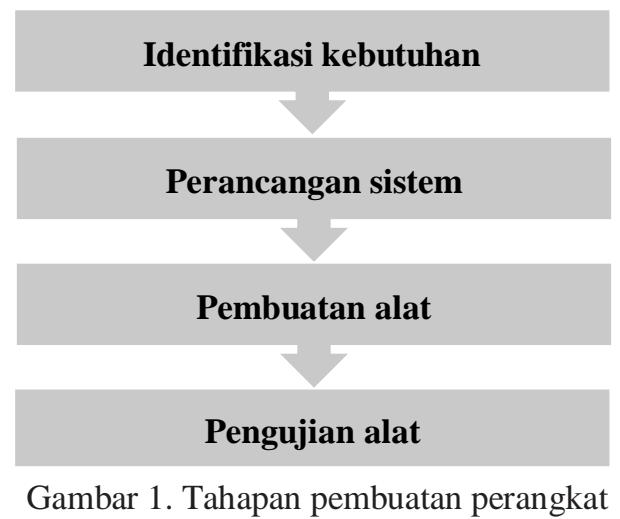

Identifikasi dan analisiss kebutuhan bertujuan untuk menentukan kebutuhan komponen yang diperlukan dalam pembuatan 
prototipe kursi roda. Perancangan sistem digunakan untuk melakukan desain sistem perangkat, baik visualisasi perangkat maupun desain kinerja. Pembuatan perangkat merupakan realisasi hasil desain pada tahap sebelumnya. Proses ini melalui beberapa tahapan. Pengujian dilakukan untuk memperoleh data dengan menggunakan dua pengujian, yaitu pengujian fungsional dan pengujian unjuk kerja.

\section{HASIL DAN PEMBAHASAN}

Kebutuhan pengembangan perangkat secara umum dapat diidentifikasikan ke dalam pembuatan empat rangkaian utama. Keempat rangkaian utama tersebut adalah rangkaian catu daya, rangkaian input, rangkaian output dan rangkaian sistem minimum. Secara rinci, penentuan kebutuhan komponen yang diperlukan dalam pembuatan protoripe kursi roda ditampilan pada Tabel 1.

Tabel 1. Kebutuhan alat dan bahan

\begin{tabular}{|c|c|c|}
\hline Rangkaian & Komponen & Spesifikasi \\
\hline Catudaya & Baterai & $\begin{array}{l}\text { Baterai lithium } 18650 \\
\text { Daya } 3,7 \mathrm{~V} \\
\text { Jumlah } 2 \text { buah dipasang } \\
\text { secara seri }\end{array}$ \\
\hline \multirow[t]{3}{*}{ Input } & $\begin{array}{l}\text { Driver motol } \\
\text { DC }\end{array}$ & Tipe modul L293D \\
\hline & Smartphone & Android 5,1 (Lolipop) \\
\hline & Joystick & $\begin{array}{l}\text { Potensiometer untuk } 2 \\
\text { axis }\end{array}$ \\
\hline Output & Motor DC & $\begin{array}{l}\text { Tegangan } 12 \mathrm{~V} \text { dengan } \\
\text { torsi } 1000 \mathrm{rpm}\end{array}$ \\
\hline Sistem & Mikrokontroleı & r Arduino nano \\
\hline \multirow{9}{*}{ mimimum } & Kabel jumper & Secukupnya \\
\hline & Kabel pelangi & Secukupnya \\
\hline & Pipa paralon & Secukupnya \\
\hline & $\mathrm{T}$ pipa paralon & 2 buah \\
\hline & $\begin{array}{l}\text { Siku pipa } \\
\text { paralon }\end{array}$ & a buah \\
\hline & Kertas karton & Secukupnya \\
\hline & $\begin{array}{l}\text { Cat besi warna } \\
\text { hitam }\end{array}$ & 1 buah \\
\hline & $\begin{array}{l}\text { Lem pipa } \\
\text { paralon }\end{array}$ & a 1 buah \\
\hline & Solasi bakar & Secukupnya \\
\hline
\end{tabular}

Blok diagram sistem keseluruhan dari prototype kursi roda ini terdiri dari tiga blok yang meliputi blok masukan, blok pemrosesan dan blok keluaran. Gambar 2 menyajikan bagian-bagian tiap blok tersebut. Secara singkat, pin dan fungsi dari arduino nano yang dirancang tersaji pada Tabel 2.

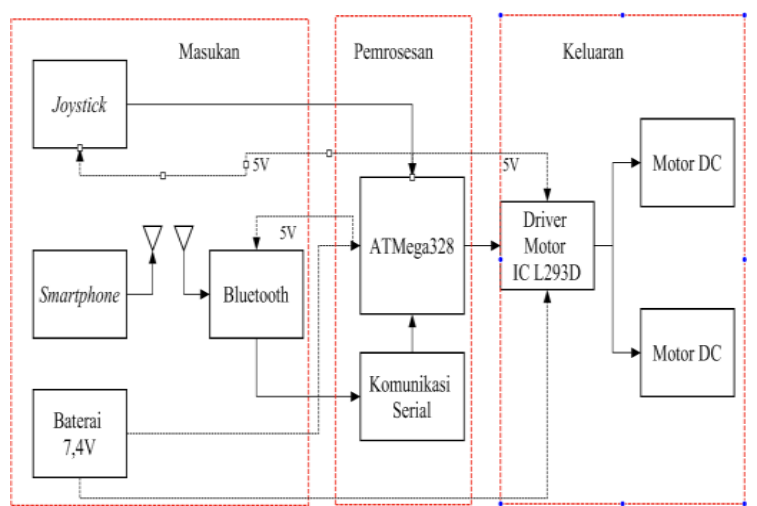

Gambar 2. Blok Diagram Sistem

Tabel 2. Pin Arduino Nano yang digunakan

\begin{tabular}{llll}
\hline Pin & No & Tipe Fungsi \\
\hline Digital & Tx & I/O & Pin attention receiver bluetooth \\
& Rx & I/O & Pin command receiver bluetooth \\
D4 & I/O & IN2 motor driver L293D \\
D5 & I/O & IN3 motor driver L293D \\
D6 & I/O & IN4 motor driver L293D \\
D11 & I/O & IN1 motor driver L293D \\
Analog & A0 & I/O & Pin VRx joystick \\
A1 & I/O & Pin VRy joystick \\
5V & I/O & Pin 5V bluetooth \\
GND & I/O & Pin GND bluetooth \\
\hline
\end{tabular}

Tahapan pembuatan perangkat yang pertama adalah perakitan prototype. Langkahlangkah perakitan prototipe terdiri atas, yaitu (1) menyiapkan alat-alat yang akan digunakan seperti satu set obeng, gunting, cutter, korek api, tenol, dan atraktor; (2) menyiapkan komponenkomponen akan digunakan serperti arduino nano, IC L293D Driver Motor DC, joystick, motor DC, modul bluetooth, catu daya berupa 2 buah baterai lithium 18650 yang disambungkan secara seri dan mempunyai tegangan sebesar 3,4 V; (3) menyambung dan menyusun kabel pada modul motor, modul bluetooth, modul joystick lalu dihubungkan dengan arduino nano; (4) menghubungkan motor DC dengan arduino nano; (5) menguji koneksi antara smartphone dengan modul bluetooth; (6) menguji gerakan motor DC dengan kontrol joystick dan kontrol smartphone; (7) merakit dan juga melakukan 
koneksi ulang antara smartphone dengan modul bluetooth. Lalu menguji ulang gerakan yang dihasilkan motor DC apakah sudah sesuai dengan pertintah yang dimasukan melalui smartphone dan juga joystick; (8) menguji seberapa jauh jarak maksimal koneksi antara smartphone dengan modul bluetooth; dan (9) memasang semua rangkaian pada prototype kursi.

Tahapan setelah perakitan prototipe adalah pembuatan Kerangka Prototype kursi roda. Tahapan tersebut terdiri atas: (1) persiapan alat yang akan digunakan seperti gergaji, lem pipa paralon, lem $G$ dan lem bakar; (2) penyiapan pipa paralon ukuran 5/8", T pipa paralon dan siku pipa paralon; (3) pembuatan desain simulator kursi roda dengan paralon; (4) pengukuran dan pemotongan pipa paralon menjadi bagian-bagian dengan ukuran yang sudah ditentukan; (5) penyambungan potonganpotongan peralon ssuai dengan desain yang sudah dibuat dengan menggunakan lem paralon; (6) pemasangan roda dan bagian-bagian lainya yang dibutuhkan; dan (7) pengujian perangkat simulator kursi roda.

Rancangan 3D diperlukan sebagai acuan dalam membangun suatu alat, dalam hal ini prototype kursi roda. Rancangan 3D tersaji pada Gambar 3(a). Terdapat beberapa komponen, Arduino Nano R3, Joystick, motor driver L293D, motor DC, modul bluetooth. Gambar 3(b) menyajikan desain dari rangkaian elektronik menggunakan software Fritzing.

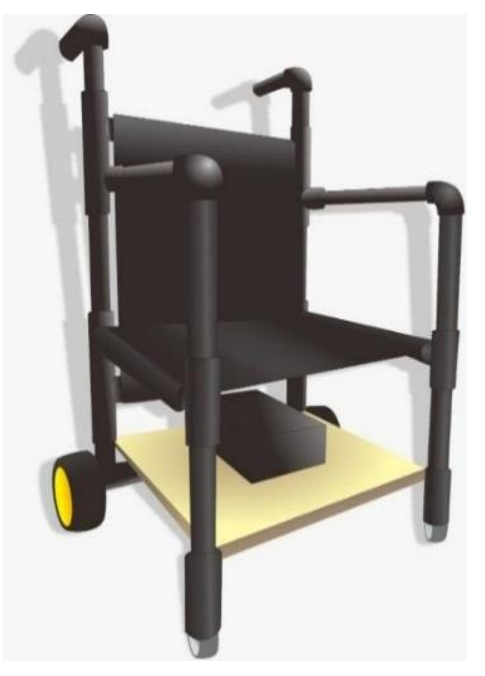

(a)

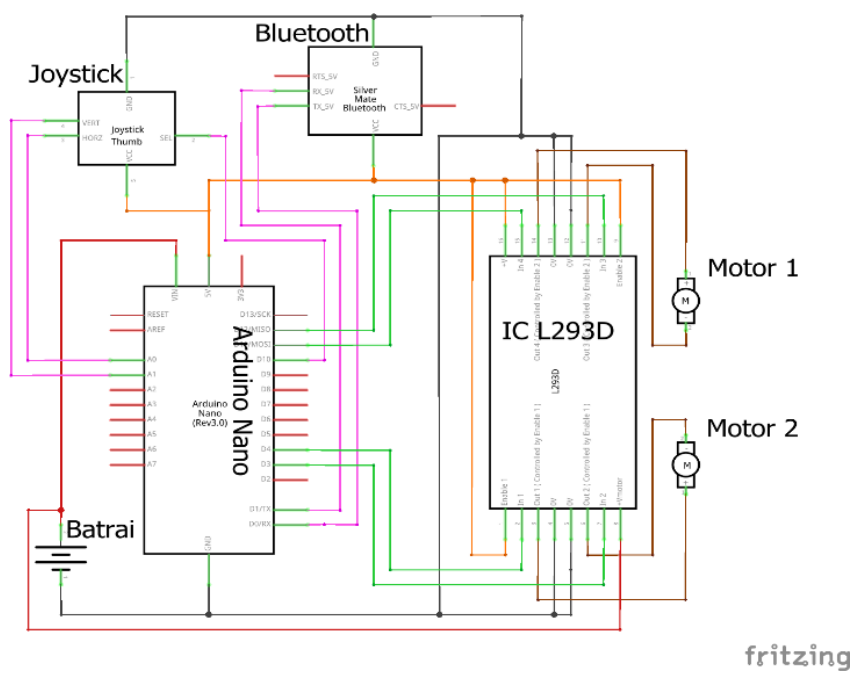

(b)

Gambar 3(a). Rancangan 3D Prototype Kursi Roda Elektrik Dengan Kendali Joystick Dan Smartphone dan Skema Elektronik

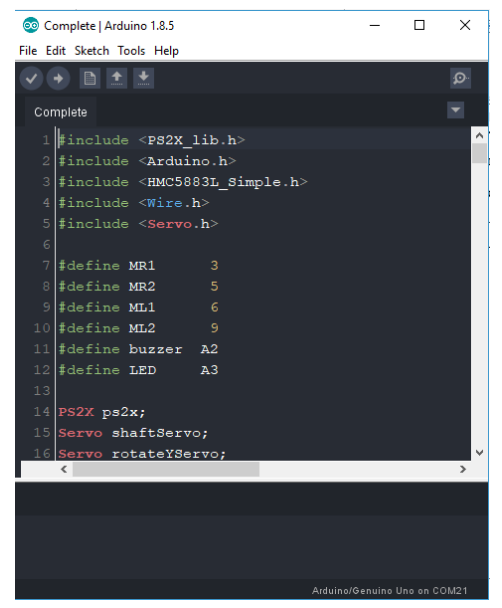

Gambar 4. Listing Program Arduino IDE
Perancangan software merupakan pembuatan sistem dengan membuat listing program yang akan dimasukkan ke dalam chip ATMega328 Arduino Nano. Pada tahap perancangan, software yang digunakan adalah Arduino IDE dengan menggunakan bahasa pemograman $\mathrm{C}$.

Pengujian fungsional dilakukan dengan cara menguji setiap rangkaian berdasarkan karakterisitik dan fungsinya. Pengukuran catu daya berfungsi untuk mengetahui tegangan yang masuk ke driver motor DC. IC L293D driver motor DC disini berfungsi sebagai penguat arus 
dan tegangan dari mikrokontroler untuk pergerakan dari motor DC. Hasil pengujian motor DC disajikan pada Tabel 3.

Tabel 3. Pengujian Tegangan Driver Motor DC

\begin{tabular}{ccccccccc}
\hline \multirow{2}{*}{ No. Variasi } & \multicolumn{3}{c}{ Vin } & \multicolumn{3}{c}{ Vout } & \multicolumn{3}{c}{ Selisih } & \multicolumn{3}{c}{ Error $(\%)$} \\
& & \multicolumn{3}{c}{ Kanan Kiri } & & Kanan & Kiri & Total \\
\hline 1 & Tanpa & 7.4 & 7.4 & 7.4 & 0 & 0 & 0 & 0 \\
& beban & 7.4 & 7.4 & 7.4 & 0 & 0 & 0 & 0 \\
& & 7.4 & 7.4 & 7.4 & 0 & 0 & 0 & 0 \\
2 & Dengan & 7.42 & 7.25 & 7.22 & 0.03 & 0.022 & 0.026 & 0.048 \\
& beban & 7.42 & 7.24 & 7.23 & 0.01 & 0.024 & 0.025 & 0.049 \\
& 7.41 & 7.24 & 7.22 & 0.02 & 0.022 & 0.025 & 0.047 \\
& \multicolumn{4}{c}{ Total Error } & & & 0.144 \\
& & \multicolumn{4}{c}{ Rerata Error } & & & 0.024 \\
\hline
\end{tabular}

Tabel 3 menunjukkan bahwa total error dari hasil pengujian motor kanan dan kiri yang sudah dilakukan sebesar $0.144 \%$, jika di persentasikan rata-rata error yang didapatkan sebesar $0,024 \%$ pada keseluruhan pengujian yang sudah dilakukan. Perbedaan tegangan yang terjadi pada percobaan ini dapat disebabkan oleh pemasangan atau penyambungan soket yang belum fix dan masih kendor. Pengujian selanjutnya disajikan pada Tabel 4.

Tabel 4. Pengujian Arus pada Robot

\begin{tabular}{ccccc}
\hline \multirow{2}{*}{ No } & \multirow{2}{*}{ Kondisi } & \multirow{2}{*}{ Jarak } & \multicolumn{2}{c}{ Apakah terkirim? } \\
& & & Ya & Tidak \\
\hline 1 & Tanpa & $1-5$ meter & $\sqrt{ }$ & - \\
& penghalang & 8 meter & $\sqrt{ }$ & - \\
& & 10 meter & $\sqrt{ }$ & - \\
\multirow{2}{*}{2} & \multirow{2}{*}{ Dengan } & 12 meter & - & $\sqrt{ }$ \\
& penghalang & 1-5 meter & $\sqrt{ }$ & - \\
& & 8 meter & $\sqrt{ }$ & - \\
& & 10 meter & $\sqrt{ }$ & - \\
& & 12 meter & - & $\sqrt{ }$ \\
\hline
\end{tabular}

Pengujian bluetooth dilakukan agar mengetahui jarak jangkauan kinerja pada bluetooth. Pengujian dilakukan dengan cara menghubungkan modul bluetooth dengan smartphone dari jarak tertentu sehingga dapat mengetahui berapa jarak maksimal kinerja dari bluetooth. Menurut hasil pengujian pertama ketika tanpa penghalang,bluetooth masih dapat terhubung dan menerima kiriman perintah dari pengguna antara jarak 1 sampai dengan 10 meter. Ketika ditambahkan jarak menjadi 11 meter, bluetooth tidak dapat konsisten terhubung dan menerima kiriman perintah. Lalu hubungan bluetooth benar-benar terputus ketika jarak ditambahka menjadi 12 meter.

Tabel 5. Pengujian Versi Android Smartphone (terinstal aplikasi)

\begin{tabular}{llcl}
\hline No & Jenis android & Hasil & Perintah \\
\hline 1 & Oreo & Teridentifikasi & Terkirim \\
2 & Nougat & Teridentifikasi & Terkirim \\
3 & Marsmellow & Teridentifikasi & Terkirim \\
4 & Lolipop & Teridentifikasi & Terkirim \\
\hline
\end{tabular}

Pengujian versi android dilakukan untuk mengetahui tingkatan versi android yang dapat menginstal dan menjalankan aplikasi pengendali. Tabel 5 menunjukkan hasil pengujian yang sudah dilakukan,didapatkan bahwa ke 4 versi android dapat diinstal aplikasi yang digunakan sebagai kontrol kendali prototype kursi roda. Ke 4 varian versi android juga dapat mengidenfikasi mudul bluetooth HC05 yang terdapat pada perangkat simulator kursi roda dan juga mengirim perintah gerakan sesuai yang diinginkan.

Pengujian unjuk kerja dilakukan untuk mengetahui bahwa prototype kursi roda beserta sistem dapat bekerja dengan baik secara keseluruhan. Pengujian perintah aplikasi smartphone Pengujian perintah dari aplikasi ini bertujuan untuk mengetahui kesesuaian perintah dengan gerakan motor DC yang dihasilkan.

\begin{tabular}{cll}
\multicolumn{2}{c}{ Tabel 6. Pengujian Perintah } & Aplikasi Smartphone \\
\hline No & Perintah yang dilakukan & Hasil respon perintah \\
\hline 1 & Maju & Benar \\
2 & Mundur & Benar \\
3 & Kanan & Benar \\
4 & Kiri & Benar
\end{tabular}

Tabel 6 menunjukkan hasil pengujian perintah aplikasi yang sudah dilakukan. Hasil terebut menunjukkan bahwa semua perintah arah gerak yang dilakukan baik arah maju,mundur, kanan dan kiri dapat dikirimkan dan diterima oleh perangkat simulator kursi roda. Semua gerakan yang dihasilkan juga sudah seseuai dengan instruksi yang diberikan tanpa adanya kendala seperti arah yang tertukar atau salah satu arah tidak berfungsi. 
Tabel 7. Pengujian Kendali Joystick

\begin{tabular}{lllll}
\hline No & $\begin{array}{c}\text { Perintah } \\
\text { yang } \\
\text { dilakukan }\end{array}$ & \multicolumn{2}{l}{ Pergerakan arah motor DC } & $\begin{array}{c}\text { Arah } \\
\text { kursi } \\
\text { roda }\end{array}$ \\
\hline 1 & Maju & Ke depan & Ke depan & Maju \\
2 & Mundur & Ke belakang & Ke belakang & Mundur \\
3 & Kanan & Ke belakang & Ke depan & Kanan \\
4 & Kiri & Ke depan & Ke belakang & Kiri \\
\hline
\end{tabular}

Pengujian kendali joystick bertujuan untuk mengetahui kesesuaian perintah yang dilakukan dengan cara menggerakan tuas modul joystick sesuai dengan arah yang diinginkan. Sesuai hasil pengujian yang sudah dilakukan pada Tabel 7, didapatkah bahwa arah putaran motor kanan dan kiri sudah sesuai dengan perintah yang dilakukan. Hasil gerakan dari simulator kursi roda juga sudah sesuai tanpa ada kendala salah arah atau ketidakfungsian arah.

Tabel 8. Pengujian Secara Keseluruhan Arah Maju dan Mundur pada jaran 2m

\begin{tabular}{lcccc}
\hline \multirow{2}{*}{$\begin{array}{c}\text { Uji } \\
\text { ke- }\end{array}$} & \multicolumn{2}{c}{ Tanpa beban } & \multicolumn{2}{c}{ Dengan beban } \\
\hline 1 & 6 & 0.34 & 7.2 & 0.27 \\
2 & 6 & 0.34 & 7.2 & 0.27 \\
3 & 6 & 0.34 & 7.2 & 0.27 \\
4 & 6 & 0.34 & 7.2 & 0.27 \\
5 & 6 & 0.34 & 7.2 & 0.27 \\
6 & 6 & 0.34 & 7.3 & 0.27 \\
7 & 6.4 & 0.31 & 7.5 & 0.27 \\
8 & 6.6 & 0.30 & 7.6 & 0.26 \\
9 & 6.8 & 0.29 & 7.6 & 0.26 \\
10 & 7 & 0.28 & 7.6 & 0.25 \\
& Rerata & 0.322 & Rerata & 0.266 \\
\hline
\end{tabular}

Tabel 9. Pengujian Secara Keseluruhan Arah Kanan dan kiri (pada jarak $0.5 \mathrm{~m}$ )

\begin{tabular}{lcccc}
\hline \multirow{2}{*}{$\begin{array}{c}\text { Uji } \\
\text { ke- }\end{array}$} & \multicolumn{2}{c}{ Tanpa beban } & \multicolumn{2}{c}{ Dengan beban } \\
\hline 1 & 1.4 & 0.35 & 1.5 & 0.33 \\
2 & 1.4 & 0.35 & 1.5 & 0.33 \\
3 & 1.4 & 0.35 & 1.5 & 0.33 \\
4 & 1.4 & 0.35 & 1.5 & 0.33 \\
5 & 1.4 & 0.35 & 1.5 & 0.33 \\
6 & 1.4 & 0.35 & 1.7 & 0.29 \\
7 & 1.47 & 0.34 & 1.7 & 0.29 \\
8 & 1.48 & 0.33 & 1.8 & 0.28 \\
9 & 1.48 & 0.33 & 1.8 & 0.26 \\
10 & 1.5 & 0.33 & 1.9 & 0.26 \\
& Rerata & 0.343 & Rerata & 0.305 \\
\hline \multicolumn{5}{c}{ Kecepatan } \\
\hline
\end{tabular}

Tabel 8 dan Tabel 9 menyajikan hasil pengujian keseluruhan. Pengujian keseluruhan dilakukan dengan dua cara yaitu dengan beban dan tanpa beban,tujuan dari pengujian ini adalah untuk mengertahui kinerja dari alat dan juga kecepatan laju dari simulator kursi roda.

Setelah dketahui waktu tempuh dan kecepatan pada masing-masing pengujian, dilakukan perhitungan kcepatan rata-ratanya pada semua arah pergerakan kursi roda. Dari Percobaan yang sudah dilakukan diketahu bahwa kecepatan pada saat pengujian tanpa beban berbeda dengan saat diuji dengan beban. Beban berpengaruh pada kekuatan motor sehigga mempengaruhi laju kecepatan simulator kursi roda. Perbedaan kecepatan juga dapat disebabkan dari kekuatan batrai yang mulai menurun karena dilakukan uji coba yang berulang-ulang, hal ini dapat dilihat dari perbedaan yang terjadi pada saat percobaan pertama sampai dengan percobaan ke 10 .

\section{SIMPULAN}

Hasil pengujian dan pembahasan yang telah dilakukan terhadap ASRO (Amphibious Spy Robot), menunjukkan bahwa rancang bangun prototype kursi roda elektrik dengan kendali joystick dan smartphone telah berhasil dibuat. Bahan rangka utama dari alat ini terbuat dari pipa paralon berukuran 5,8. Prototype kursi roda menggunakan 2 buah pengendalian yaitu dengan joystick dan smartphone. Modul bluetooth HC-05 dibutuhkan sebagai penghubung antara smartphone dengan prototype kursi roda. Masukan pengendalian yang sudah dikirimkan kemudian diproses dengan mikrokontroler ATMega328 (Arduino nano). Data yang sudah diproses kemudian dikuatkan dengan driver motor IC L293D, hasil penguatan digunakan untuk masukan pergerakan 2 buah motor. Rangkaian elektronika dikemas dalam black box yang memiliki ukuran $18 \times 11$ x 6 agar aman ketika prototype kursi roda sedang dioprasikan. Flowchart dan koding pada sistem bekerja dengan baik sehingga eror yang terjadi sangat kecil. Pembuatan flowchart 
menggunakan software ClickChart, sedangkan pembuatan koding untuk mikrokontroler ATMEGA328 (Arduino nano) dengan software Arduino IDE menggunakan bahasa C. List program yang sudah dibuat, berfungsi untuk menjalankan sistem dari prototype kursi roda elektrik dengan kendali joystick dan smartphone. Unjuk kerja dan cara kerja dari prototype kursi roda berdasarkan hasil pengujian yang telah dilakukan dapat berfungsi dengan baik antara masukan, proses dan keluaran. Persentase eror yang terjadi pada saat pengujian dengan beban dan tanpa beban sebesar 0,024\%. Jarak maksimal dari kendali smartphone dapat terhubung dan mengirimkan perintah pada protype kursi roda sejauh 10 meter, koneksi antara smartphone dengan prototype kursi roda terputus pada saat jarak 12 meter. Aplikasi smartphone yang digunakan sebagai kendali protype kursi roda dapat diinstall dan dijalankan pada varian versi android terbaru "nougat" sampai dengan 3 versi dibawahnya.. Laju kecepatan simulator kursi roda pada mode kendali joystick bergantung pada resistansi yang dikeluarkan dari modul joystick. Kecepatan dengan kendali smartphone belum dapat diatur sesuai dengan keinginan dari pengguna

\section{DAFTAR PUSTAKA}

[1] M. Sosial, Lampiran I Peraturan Menteri Sosial Republik Indonesia Nomor 186 Tahun 2011 Tentang Rencana Strategis Kementerian Sosial Tahun 2010-2014. Indonesia: http://ditjenpp.kemenkumham.go.id/arsip/bn/20 12/bn91-2012lamp.pdf, 2011.
[2] M. T. Nuryetty, Kesulitan Fungsional Penduduk Indonesia: Hasil Sensus Penduduk Indonesia 2010. Jakarta: Badan Pusat Statistik.

[3] A. Wibowo, "80 Persen Pengguna Kursi Roda di Yogyakarta Miskin,” Tempo.co, 2010. [Online]. Available:

https://nasional.tempo.co/read/235838/80persen-pengguna-kursi-roda-di-yogyakartamiskin.

[4] R. Syam and Mustari, "Rancang Bangun Kursi Roda Elektrik untuk Kondisi Naik Turun Tanjakan," J. Mek., vol. 2, no. 2, pp. 147-155, 2011.

[5] Iksal and Darmo, "Perancangangan dan Implementasi Kursi Roda Elektrik Ekonomis Sebagai Sarana Rehabilitasi Medik," in Prosiding SNaPP2012: Sains, Teknologi, dan Kesehatan, 2012, pp. 203-210.

[6] A. M. N. Imron, W. Muldayani, and Sumardi, "Perintah Kontrol Gerak Kursi Roda Elektrik Menggunakan Sensor Elektromiograf," $J$. Rekayasa Elektr., vol. 15, no. 1, pp. 56-60, 2019.

[7] Mawardi and J. Lianda, "Rancang Bangun Kursi Roda Elektrik Menggunakan Joystick," in Seminar Nasional Industri dan Teknologi (SNIT), Politeknik Negeri Bengkalis Rancang, 2018, pp. 67-74.

[8] D. A. Abrianto, I. Setiawan, and A. Hidayatno, "Kontrol Kursi Roda Cerdas menggunakan pergerakan kepala," in Makalah Seminar Tugas Akhir Jurusan Teknik Elektro UNDIP, 2012.

[9] B. S. Utomo, "Kursi Roda Terkendali Otomatis Speech Recognition Dengan Bluetooth Berbasis Android," UNY, 2018.

[10]Liem Yuliana Kathina Hatta, Pujiono, and Tasripan, "Rancang Bangun Kursi Roda Elektrik Menggunakan Perintah Suara Berbasis Aplikasi Android," J. Tek. Pomits, vol. 1, no. 1, pp. 1-6, 2012. 